\title{
CRISPR-mediated gene editing to rescue haploinsufficient obesity syndrome
}

\author{
Zhifeng Wang ${ }^{1,2}$, Liu Yang ${ }^{3}$, Shen $\mathbf{Q u}^{3 凶}$, Chao Zhang ${ }^{1 凶}$ \\ ${ }^{1}$ Translational Medical Center for Stem Cell Therapy and Institute for Regenerative Medicine, Shanghai East Hospital, \\ Shanghai Key Laboratory of Signaling and Disease Research, School of Life Sciences and Technology, Tongji University, \\ Shanghai 200092, China \\ ${ }^{2}$ Research \& Development Department, Sinoneural Cell and Gene Engineering Holdings Co., Ltd., Shanghai, China \\ ${ }^{3}$ Department of Endocrinology and Metabolism, National Metabolic Management Center, Shanghai Tenth People's Hospital, \\ School of Medicine, Tongji University, Shanghai 200092, China \\ $\triangle$ Correspondence: qushencn@hotmail.com (S. Qu), zhangchao@tongji.edu.cn (C. Zhang)
}

CRISPR and adeno-associated virus are becoming powerful tools to remedy genetic disorders in somatic cells of adulthood. A recent study published in Science (Matharu et al., 2019) safely targeted the non-coding genomic region of Sim1 and MC4R with rAAV packed with CRISPRa, and successfully rescued the obesity syndrome caused by haploinsufficiency in a murine model, which shed light on their potential therapeutic applications in the future (Matharu et al., 2019).

CRISPR-Cas9, first described as an adaptive immune system in bacteria, has now been developed as RNA-guided endonucleases for genome editing. As the fourth approach after meganucleases, Zinc-finger nucleases (ZFN) and transcription activator-like effectors nucleases (TALENs), this system has also been broadly used to perform "loss-offunction" and "gain-of-function" genetic studies to determine the roles of specific genes in cells or animals. The endogenous gene transcription could be modulated by means of manipulation of Transcription activator- like effectors (TALEs) or Zinc-fingers (ZFs) fused to transcriptional regulators (Sera, 2009; Chapdelaine et al., 2016). However, despite their efficacy, the exploitation of TALE and ZFs tools requires complex and time-consuming assembly protocols. Among the emerging applications of CRISPR-Cas 9 based gene editing are techniques that incorporate a catalytically deactivated Cas9 (dCas9) fused to a protein domain to regulate transcription (Boettcher and McManus, 2015). Single guiding RNAs (sgRNA) target dCas9 fusion proteins to specific DNA segments such as promoters and enhancers, which may lead to activation (CRISPRa) or interference

Zhifeng Wang and Liu Yang have contributed equally to this work.
(CRISPRi) of transcription depending on the property of fused DNA cassette. Rosa26 knock-in constructs coupled with Cre/loxP recombination system have achieved conditional overexpression of exogenous genes in specific tissues, and also allow for site-specific integration of super large fragments (20-30 kb) (Hohenstein et al., 2008). However, this system generally needs complex knock-in operations and multiple-crossing schemes to generate desired mouse strains, which results into severe impact on the efficiency of the system. Bacterial artificial chromosome (BAC) based random transgenosis, as an alternative approach to overexpress a specific gene in animal model, can quickly and efficiently obtain the transgenic founder of mice. However, due to the integration of the gene cassette into a random locus, this technique may cause unwanted mutations and genes flanking the insertion site could be silenced unpredictably (Shinohara et al., 2007). Fortunately, the CRISPRa/dCas9 system possesses the potential to overcome these barriers described above. Numerous studies have demonstrated that the CRISPRa system is highly effective and easily tailorable to increase gene expression, or correct disease-causing mutations, with potential intriguing implications for therapy of human diseases (Matharu et al., 2019; Pignani et al., 2019; Savell et al., 2019). Nevertheless, plenty of room remains for further improvement and technical extensions on this system. The off-target mutagenesis was the initial concern about the therapeutic applications of CRISPRa system (Akcakaya et al., 2018). Another, but not the last, key question is how to efficiently deliver CRISPR-Cas9 into those tissues or cell types that are hard to infect or transfect (Ma et al., 2014). Fortunately, recombinant adeno-associated virus (rAAV) has so for 
become a most commonly used vehicle for CRISPR-Cas9 delivery because of its high efficacy, long-lasting transgene expression, less potential of immunogenic effect, and nonintegration feature without random genomic insertion (Liu et al., 2017).

Harnessed as an effective genome editor, CRISPR-Cas9 has been broadly used in biomedical engineering of somatic cells (Liang et al., 2015; Cohen, 2018), and also been demonstrated as a promising tool to treat genetic disorders in model systems ranging from cells in vitro to animals in vivo. For example, it can restore dystrophin protein expression in cardiac and skeletal muscle by correcting mutations responsible for Duchenne muscular dystrophy (DMD) (Long et al., 2016; Nelson et al., 2016; Tabebordbar et al., 2016; Amoasii et al., 2018). In the case of cardiovascular disease, CRISPR gene editing can greatly reduce serum levels of PCSK9 and total cholesterol by targeting the PCSK9 gene in hepatocytes in vivo (Ding et al., 2014; Wang et al., 2016; Rossidis et al., 2018; Wang et al., 2018). Additionally, in vivo CRISPR-Cas9 gene editing prevents inherited retinal degeneration through selective ablation of S334ter mutation in a rat model of autosomal dominant retinitis pigmentosa (Bakondi et al., 2016). Moreover, CRISPR-Cas9 editing system is being explored for treating acquired diseases, such as cancer, HIV and hepatitis B (Seeger and Sohn, 2014; Soriano, 2017; Xiong et al., 2019). Nevertheless, successful correction of obesity-associated mutations in vivo via the CRISPR-Cas 9 system has not yet been reported.

Single minded family basic helix-loop-helix transcriptional factor 1 (SIM1), a factor essential for neuronal differentiation and function of paraventricular nuclei (PVN) in the hypothalamus, plays a central role in food intake and energy homeostasis. Haploinsufficiency of Sim1, where one of the two gene copies is functionally lost, develops early-onset obesity with increased linear growth, hyperphagia, hyperinsulinemia and hyperleptinemia but no change in energy expenditure (Michaud et al., 2001). Hypothalamic Sim1 overexpression rescued diet-induced obesity due to reduced food intake (Kublaoui et al., 2006). Melanocortin-4 receptor (MC4R), a G protein-coupled receptor (GPCR) expressed in the hypothalamus, plays an important role in the appetite control and energy homeostasis (Huszar et al., 1997; Balthasar et al., 2005). MC4R expressed on glutamatergic Sim1 neurons in the PVN is both necessary and sufficient for the regulation of body weight (Balthasar et al., 2005; Xu et al., 2013; Shah et al., 2014). Haploinsufficiency of MC4R produces massive obesity in humans, while haplo-inactivation of MC4R in mice results in hyperphagic obesity (Huszar et al., 1997; Vaisse et al., 2000; Farooqi et al., 2003). In a very recent report, Matharu et al. utilized CRISPRa/dCas9 system to restore the expression of the haploinsufficient genes, Sim1 and MC4R, to physiological level in mouse models (Matharu et al., 2019). Different from canonical genome editing to correct disease causing DNA mutations, in this study, Matharu fused VP64, a universal moderate transcriptional activator to nuclease-deficient Cas9 (dCas9) to targets the promoter or enhancer, the non-coding genomic region of the remaining functional $\operatorname{Sim} 1$ gene to up-regulate endogenous gene expression. To examine the specificity and effectiveness of the approach, Matharu employed the transgenic animals carrying spdCas9-VP64, as well as rAAV mediated delivery of $p C M V$-spdCas9-VP64 directly into the PVN of hypothalamus. In both cases, hypothalamic Sim1 expression restored to normal levels and thus rescued the obesity syndrome. Moreover, both hypothalamic transcriptome and ChIP-seq analysis showed that none of the Sim1 neighboring genes within a 500-kb window was differentially expressed, demonstrating the high specificity of this approach. Injecting rAAV-based CRISPRa into the hypothalamus of MC4R haploinsufficient mice similarly rescues the weight gain phenotype, further demonstrating the strength of this approach. This report presented us the first in vivo utilization of CRISPR-Cas9 system to rescues obesity due to haploinsufficient gene deficiency occurred in the central nerve system.

Moreover, this study also provides us with new strategy to treat obesity caused by abnormal gene expression: CRISPRa for haploinsufficient genes as reported in this study, or CRISPRi to treat diseases caused by pathogenic overexpression of a gene. Besides SIM1 and MC4R, the haploinsufficiency of proprotein convertase 1 (PCSK1), melanocortin 2 receptor accessory protein 2 (MRAP2) in the brain, iroquois homeobox 3 (IRX3) in fat or uncoupling protein 3 (UCP3) in mitochondria are also responsible for human obesity (Argyropoulos et al., 1998; Creemers et al., 2012; Asai et al., 2013; Zou et al., 2017). While overexpression of FTO, 11ß-hydroxysteroid dehydrogenase-1 (11ß-HSD-1), paternally expressed Mest (Peg1) in adipose tissue can also result in obesity (Kannisto et al., 2004; Rankinen et al., 2006; Church et al., 2010). These studies demonstrated that disrupting the expression of these genes may also rescue obesity by using CRISPRi technique. These results presented by Matharu et al. suggested that rAAV-mediated delivery of CRISPRa or CRISPRi targeting to cis-regulatory elements of these obesity-causing genes may be a better way, because this approach only regulates gene expression without modifying the coding region, thus expanding the options for choosing target and avoiding potential off-target mutations. While identifying and carefully characterizing the promoters and enhancers of these obesity-caused genes should be the primary issue that we need to address. Nevertheless, strict ethical argument and monitoring regulation are essential when carrying out this therapeutic strategy in human patients in the near future.

\section{ACKNOWLEDGEMENTS}

The work was supported by grants from National Key Research and Development Program of China (Grant No. 2017YFA0103902); The National Natural Science Foundation of China (Grant Nos. 
81570760 and 31771283); the Fundamental Research Funds for the Central Universities of Tongji University.

\section{OPEN ACCESS}

This article is distributed under the terms of the Creative Commons Attribution 4.0 International License (http://creativecommons.org/ licenses/by/4.0/), which permits unrestricted use, distribution, and reproduction in any medium, provided you give appropriate credit to the original author(s) and the source, provide a link to the Creative Commons license, and indicate if changes were made.

\section{REFERENCES}

Akcakaya P, Bobbin ML, Guo JA, Malagon-Lopez J, Clement K, Garcia SP, Fellows MD, Porritt MJ, Firth MA, Carreras A et al (2018) In vivo CRISPR editing with no detectable genome-wide off-target mutations. Nature 561:416-419

Amoasii L, Hildyard JCW, Li H, Sanchez-Ortiz E, Mireault A, Caballero D, Harron R, Stathopoulou TR, Massey C, Shelton JM et al (2018) Gene editing restores dystrophin expression in a canine model of Duchenne muscular dystrophy. Science 362:8691

Argyropoulos G, Brown AM, Willi SM, Zhu J, He Y, Reitman M, Gevao SM, Spruill I, Garvey WT (1998) Effects of mutations in the human uncoupling protein 3 gene on the respiratory quotient and fat oxidation in severe obesity and type 2 diabetes. $\mathrm{J}$ Clin Investig 102:1345-1351

Asai M, Ramachandrappa S, Joachim M, Shen $\mathrm{Y}$, Zhang R, Nuthalapati N, Ramanathan V, Strochlic DE, Ferket P, Linhart K et al (2013) Loss of function of the melanocortin 2 receptor accessory protein 2 is associated with mammalian obesity. Science 341:275-278

Bakondi B, Lv W, Lu B, Jones MK, Tsai Y, Kim KJ, Levy R, Akhtar AA, Breunig JJ, Svendsen CN et al (2016) In vivo CRISPR/Cas9 gene editing corrects retinal dystrophy in the S334ter-3 rat model of autosomal dominant retinitis pigmentosa. Mol Ther 24:556563

Balthasar N, Dalgaard LT, Lee CE, Yu J, Funahashi H, Williams T, Ferreira M, Tang V, McGovern RA, Kenny CD et al (2005) Divergence of melanocortin pathways in the control of food intake and energy expenditure. Cell 123:493-505

Boettcher M, McManus MT (2015) Choosing the right tool for the job: RNAi, TALEN, or CRISPR. Mol Cell 58:575-585

Chapdelaine P, Gerard C, Sanchez N, Cherif K, Rousseau J, Ouellet DL, Jauvin D, Tremblay JP (2016) Development of an AAV9 coding for a 3XFLAG-TALEfrat\#8-VP64 able to increase in vivo the human frataxin in YG8R mice. Gene Ther 23:606-614

Church C, Moir L, McMurray F, Girard C, Banks GT, Teboul L, Wells S, Bruning JC, Nolan PM, Ashcroft FM et al (2010) Overexpression of Fto leads to increased food intake and results in obesity. Nat Genet 42:1086-1092

Cohen J (2018) In dogs, CRISPR fixes a muscular dystrophy. Science 361:835

Creemers JW, Choquet H, Stijnen P, Vatin V, Pigeyre M, Beckers S, Meulemans S, Than ME, Yengo L, Tauber M et al (2012)
Heterozygous mutations causing partial prohormone convertase 1 deficiency contribute to human obesity. Diabetes 61:383-390

Ding Q, Strong A, Patel KM, Ng SL, Gosis BS, Regan SN, Cowan CA, Rader DJ, Musunuru K (2014) Permanent alteration of PCSK9 with in vivo CRISPR-Cas9 genome editing. Circ Res 115:488-492

Farooqi IS, Keogh JM, Yeo GS, Lank EJ, Cheetham T, O'Rahilly S (2003) Clinical spectrum of obesity and mutations in the melanocortin 4 receptor gene. N Engl J Med 348:1085-1095

Hohenstein P, Slight J, Ozdemir DD, Burn SF, Berry R, Hastie ND (2008) High-efficiency Rosa26 knock-in vector construction for Cre-regulated overexpression and RNAi. Pathogenetics 1:3

Huszar D, Lynch CA, Fairchild-Huntress V, Dunmore JH, Fang Q, Berkemeier LR, Gu W, Kesterson RA, Boston BA, Cone RD et al (1997) Targeted disruption of the melanocortin-4 receptor results in obesity in mice. Cell 88:131-141

Kannisto K, Pietilainen KH, Ehrenborg E, Rissanen A, Kaprio J, Hamsten A, Yki-Jarvinen H (2004) Overexpression of 11betahydroxysteroid dehydrogenase-1 in adipose tissue is associated with acquired obesity and features of insulin resistance: studies in young adult monozygotic twins. J Clin Endocrinol Metab 89:4414-4421

Kublaoui BM, Holder JL Jr, Tolson KP, Gemelli T, Zinn AR (2006) SIM1 overexpression partially rescues agouti yellow and dietinduced obesity by normalizing food intake. Endocrinology 147:4542-4549

Liang $\mathrm{P}, \mathrm{Xu} \mathrm{Y}$, Zhang $\mathrm{X}$, Ding C, Huang R, Zhang Z, Lv J, Xie X, Chen Y, Li Y et al (2015) CRISPR/Cas9-mediated gene editing in human tripronuclear zygotes. Protein Cell 6:363-372

Liu C, Zhang L, Liu H, Cheng K (2017) Delivery strategies of the CRISPR-Cas9 gene-editing system for therapeutic applications. J Control Release 266:17-26

Long C, Amoasii L, Mireault AA, McAnally JR, Li H, Sanchez-Ortiz E, Bhattacharyya S, Shelton JM, Bassel-Duby R, Olson EN (2016) Postnatal genome editing partially restores dystrophin expression in a mouse model of muscular dystrophy. Science 351:400-403

Ma Y, Zhang L, Huang X (2014) Genome modification by CRISPR/ Cas9. FEBS J 281:5186-5193

Matharu N, Rattanasopha S, Tamura S, Maliskova L, Wang Y, Bernard A, Hardin A, Eckalbar WL, Vaisse C, Ahituv N (2019) CRISPR-mediated activation of a promoter or enhancer rescues obesity caused by haploinsufficiency. Science 363:eaau0629

Michaud JL, Boucher F, Melnyk A, Gauthier F, Goshu E, Levy E, Mitchell GA, Himms-Hagen J, Fan CM (2001) Sim1 haploinsufficiency causes hyperphagia, obesity and reduction of the paraventricular nucleus of the hypothalamus. Hum Mol Genet 10:1465-1473

Nelson CE, Hakim CH, Ousterout DG, Thakore PI, Moreb EA, Castellanos Rivera RM, Madhavan S, Pan X, Ran FA, Yan WX et al (2016) In vivo genome editing improves muscle function in a mouse model of Duchenne muscular dystrophy. Science 351:403-407

Pignani S, Zappaterra F, Barbon E, Follenzi A, Bovolenta M, Bernardi F, Branchini A, Pinotti M (2019) Tailoring the CRISPR system to transactivate coagulation gene promoters in normal and mutated contexts. Biochim Biophys Acta Gene Regul Mech. https://doi.org/10.1016/j.bbagrm.2019.04.002 
Rankinen T, Zuberi A, Chagnon YC, Weisnagel SJ, Argyropoulos G, Walts B, Perusse L, Bouchard C (2006) The human obesity gene map: the 2005 update. Obesity 14:529-644

Rossidis AC, Stratigis JD, Chadwick AC, Hartman HA, Ahn NJ, Li H, Singh K, Coons BE, Li L, Lv W et al (2018) In utero CRISPRmediated therapeutic editing of metabolic genes. Nat Med 24:1513-1518

Savell KE, Bach SV, Zipperly ME, Revanna JS, Goska NA, Tuscher JJ, Duke CG, Sultan FA, Burke JN, Williams D et al (2019) A neuron-optimized CRISPR/dCas9 activation system for robust and specific gene regulation. eNeuro. https://doi.org/10.1523/ ENEURO.0495-18.2019

Seeger C, Sohn JA (2014) Targeting hepatitis B virus with CRISPR/ Cas9. Mol Ther Nucleic Acids 3:e216

Sera T (2009) Zinc-finger-based artificial transcription factors and their applications. Adv Drug Deliv Rev 61:513-526

Shah BP, Vong L, Olson DP, Koda S, Krashes MJ, Ye C, Yang Z, Fuller PM, Elmquist JK, Lowell BB (2014) MC4R-expressing glutamatergic neurons in the paraventricular hypothalamus regulate feeding and are synaptically connected to the parabrachial nucleus. Proc Natl Acad Sci USA 111:13193-13198

Shinohara ET, Kaminski JM, Segal DJ, Pelczar P, Kolhe R, Ryan T, Coates CJ, Fraser MJ, Handler AM, Yanagimachi R et al (2007) Active integration: new strategies for transgenesis. Trans Res 16:333-339

Soriano V (2017) Hot news: gene therapy with CRISPR/Cas9 coming to age for HIV cure. AIDS Rev 19:167-172
Tabebordbar M, Zhu K, Cheng JKW, Chew WL, Widrick JJ, Yan WX, Maesner C, Wu EY, Xiao R, Ran FA et al (2016) In vivo gene editing in dystrophic mouse muscle and muscle stem cells. Science 351:407-411

Vaisse C, Clement K, Durand E, Hercberg S, Guy-Grand B, Froguel $P$ (2000) Melanocortin-4 receptor mutations are a frequent and heterogeneous cause of morbid obesity. J Clin Investig 106:253262

Wang L, Smith J, Breton C, Clark P, Zhang J, Ying L, Che Y, Lape J, Bell P, Calcedo R et al (2018) Meganuclease targeting of PCSK9 in macaque liver leads to stable reduction in serum cholesterol. Nat Biotechnol 36:717-725

Wang X, Raghavan A, Chen T, Qiao L, Zhang Y, Ding Q, Musunuru K (2016) CRISPR-Cas9 targeting of PCSK9 in human hepatocytes in vivo-brief report. Arterioscler Thromb Vasc Biol 36:783786

Xiong L, Wu F, Wu Q, Xu L, Cheung OK, Kang W, Mok MT, Szeto LLM, Lun CY, Lung RW et al (2019) Aberrant enhancer hypomethylation contributes to hepatic carcinogenesis through global transcriptional reprogramming. Nat Commun 10:335

Xu Y, Wu Z, Sun H, Zhu Y, Kim ER, Lowell BB, Arenkiel BR, Xu Y, Tong Q (2013) Glutamate mediates the function of melanocortin receptor 4 on Sim1 neurons in body weight regulation. Cell Metab 18:860-870

Zou Y, Lu P, Shi J, Liu W, Yang M, Zhao S, Chen N, Chen M, Sun Y, Gao A et al (2017) IRX3 promotes the browning of white adipocytes and its rare variants are associated with human obesity risk. EBioMedicine 24:64-75 